\title{
Effect of high temperature on the behavior of basalt textile reinforced refractory concrete under uniaxial tensile loading
}

\author{
Dimas Alan Strauss Rambo ${ }^{1}$, Flávio de Andrade Silva ${ }^{2}$ and Romildo Dias Toledo Filho ${ }^{3}$ \\ ${ }^{1}$ Department of Civil Engineering, Universidade Federal do Rio de Janeiro (COPPE/UFRJ), \\ P.O. Box 68506, 21945 -970, Rio de Janeiro, RJ, Brazil, dimasrambo@gmail.com \\ ${ }^{2}$ Department of Civil Engineering, Pontifícia Universidade Católica do Rio de Janeiro (PUC- \\ Rio), Rua Marques de São Vicente 225, 22451-900 - Rio de Janeiro - RJ, Brazil, \\ fsilva@puc-rio.br \\ ${ }^{3}$ Department of Civil Engineering, Universidade Federal do Rio de Janeiro (COPPE/UFRJ), \\ P.O. Box 68506, 21945 -970, Rio de Janeiro,RJ, Brazil, toledo@coc.ufrj.br
}

\begin{abstract}
The work in hand presents the preliminary results of an experimental investigation on the thermo-mechanical properties of a textile refractory composite reinforced with basalt fibers under tensile loading. The composites were produced as a laminate material using five basalt bi-directional fabric layers as reinforcement. A high alumina cement matrix was used in the matrix composition which was designed using the compressible packing method. A series of uniaxial tensile tests was performed under temperatures ranging from 25 to $1000^{\circ} \mathrm{C}$. Thermogravimetry analysis were used to study the deterioration/phase changes as a function of the studied temperatures. Scanning electron microscopy (SEM) was used to study the damage processes in the fiber-matrix interfaces after exposure to high temperatures.
\end{abstract}

Keywords: thermo-mechanical properties, textile reinforced concrete, basalt fiber, high temperatures.

\section{Introduction}

Textile reinforced concrete (TRC) are a new generation of cementitious materials with enhanced tensile strength and ductility $[1,2]$. With its excellent mechanical properties, the TRC's are used, actually, in a wide range of applications that include: strengthening and repair in structural elements, protective linings, thin-walled elements, facade elements, bridges and also freeform and lightweight structures. It's important to consider, however, that in many of these applications the concrete and the textile undergoes thermal effects, becoming the study of thermo-mechanical performance of TRC absolutely indispensable $[3,4,5]$. The aim of this article is to investigate the effect of elevated temperatures on the mechanical properties of a textile refractory composite reinforced with basalt fibers submitted to tensile loading. At first, the refractory composites were produced with a cementitious matrix, made of calcium aluminate aggregates and calcium aluminate cement, reinforced with low-cost basalt fabrics. The composites were tested under temperatures ranging from 25 to $1000^{\circ} \mathrm{C}$. The processing method used for making bi-directional reinforced composites is described and then, tensile responses of the composites are reported.

\section{Materials and mix design}

The matrix used in this research (compressive strength of about 45MPa) was designed following the compressible packing model (CPM) routine [6,7] and then adapted to the rheology necessary to produce laminated TRC's. The materials used in 
the TRC composition were a Brazilian calcium aluminate cement (Secar 51) with alumina content of approximately $50 \%$, a synthetic calcium aluminate aggregate (with an alumina content of approximately $40 \%$ ) ranging from $0.001 \mathrm{~mm}$ to $1.18 \mathrm{~mm}$ and a polycarboxilate superplasticizer in powder. The water/cementitious material ratio of the refractory concrete was 0.35 . Table 1 gives the composition of concrete matrix.

Table 1. Mix composition.

\begin{tabular}{lc}
\hline Composition & Amount \\
\hline Dense aggregate $\left(\mathrm{kg} / \mathrm{m}^{3}\right)$ & 1416.2 \\
Cement $\left(\mathrm{kg} / \mathrm{m}^{3}\right)$ & 750 \\
Superplasticizer $\left(\mathrm{kg} / \mathrm{m}^{3}\right)$ & 4.87 \\
Viscosity modifier agent - VMA $\left(\mathrm{kg} / \mathrm{m}^{3}\right)$ & 0.562 \\
Water $\left(\mathrm{kg} / \mathrm{m}^{3}\right)$ & 262.6 \\
Superplasticizer content $(\%)$ & 0.65 \\
Water/cementitious material ratio & 0.35 \\
\hline
\end{tabular}

A basalt textile commercialized by the chinese company Zhejiang GBF Basalt Fiber Co. Ltd. was used as reinforcement for the TRC specimens. The basalt textile was produced with a styrene-acrylic latex coating $\left(43 \mathrm{~g} / \mathrm{m}^{2}\right)$. The warp as well as the weft is formed by about 800 monofilaments with average diameter of $13 \mu \mathrm{m}$. The refractory concretes were produced in a room with controlled temperature of $24^{\circ} \mathrm{C} \pm 1{ }^{\circ} \mathrm{C}$ using a planetary mixer (previously moistured) of 5 liters capacity. The cementitious materials were homogenized by dry mixing for 60 seconds prior to the addition of water. The mixture was blended for 5 minutes. The VMA was added after 4 minutes of mixing. The specimens were covered in their molds for 24 hours prior to moist curing for 7 days in a cure chamber with $100 \% \mathrm{RH}$ and $24 \pm 1^{\circ} \mathrm{C}$. Rectangular plates measuring $400 \mathrm{~mm} \mathrm{x}$ $250 \mathrm{~mm} \times 13 \mathrm{~mm}$ (length $\mathrm{x}$ width $\mathrm{x}$ thickness) were produced for direct tensile tests using a lamination technique. For the production of the plates, the concrete mixtures were placed in the acrylic molds. The process started with a thin concrete layer placed on the bottom surface of the mold. The second phase consisted on positioning the first fabric of basalt textile reinforcement over the fresh concrete. The basalt textile was then pre-stressed manually, pressed and smoothed in order to regularize and align the surface of the layer. After the second phase, the procedure was repeated until reaching the desired number of 5 textile layers. Samples without textile layers were also produced. The samples suffered manual vibration. After 7 days, the rectangular plates were cut, resulting in 4 specimens of $400 \mathrm{~mm}$ x $60 \mathrm{~mm}$ x $13 \mathrm{~mm}$ (length $\mathrm{x}$ width $\mathrm{x}$ thickness).

\section{Experimental Testing Procedure}

\subsection{Heating treatment}

The tensile test specimens were heated up to $75,150,200,300,400,600$ and $1000^{\circ} \mathrm{C}$ and subsequently cooled inside the oven. Experiments on specimens stored at room temperature were also carried out. The heating regime was applied to the specimens at an age of 7 days. An electric oven with radiant heating (metal alloy type Kanthal "A1" in alumina tubes) internally protected by perforated ceramic plates was used. All samples were subject to a heating rate of $10{ }^{\circ} \mathrm{C} / \mathrm{min}$ in an oven with maximum temperature of $1100^{\circ} \mathrm{C}$. The temperature level was kept constant for 60 min in each target temperature. The specimens were then cooled down inside the oven in order to prevent thermal shock. The rate of cooling was not controlled. Before and after the heating process, the fiber-matrix interfaces were investigated using a scanning electron microscope(SEM) FEI Quanta 400. The samples were coated with approximately 20nm of gold to become more conductive and suitable for SEM analysis. The SEM was operated using $25 \mathrm{kV}$ of acceleration tension and about 30mm of working distance.

\subsection{Mechanical Testing}

The direct tensile tests on the TRC plates were performed in a Shimadzu universal testing machine model AGX - $100 \mathrm{kN}$ and controlled by the actuator displacement at a rate of $0.4 \mathrm{~mm} / \mathrm{min}$. The force was transferred to the specimens via rotatable steel plates screwed to the TRC plates. Deformation of TRC's was measured using two LVDT's. Four rectangular shaped specimens measuring $400 \mathrm{~mm}$ x $60 \mathrm{~mm} \times 13 \mathrm{~mm}$ (length $\mathrm{x}$ width $\mathrm{x}$ thickness) were tested using a gage length of $200 \mathrm{~mm}$ with fixed-hinged boundary conditions. The tensile load and actuator displacement were recorded.

\section{Discussion and analyses}

The produced TRC showed to be strongly affected by thermal processing when submitted to a tensile loading. Likewise, the mechanical properties of the basalt yarn as well as the basalt fabric were also influenced. Figure 1 presents one representative curve obtained from the TRC in the direct tensile test for each target temperature investigated in the present work. The stressstrain curves were depicted in 3 distinct stages using roman numerals, each one with its elastic modulus. The stage I corresponds to the elastic-linear range where both matrix and fiber behave linearly. The post BOP stage is characterized by formation of distributed cracking (stage II). In this phase, as the applied strain increases, more cracks form culminating in a 
multiple cracking pattern along the sample. The stage III, is characterized by a crack-widening phase that starts at the end of phase II $\left(\varepsilon_{\mathrm{t}, \text { II }}\right)$, leading to a stretching of the fabric and, posteriorly, failure of the composite. The results of evaluation of all curves are given in Table 2. As expected, strain-hardening behavior was observed for the TRC's in the majority of target temperatures, excluding only $600^{\circ} \mathrm{C}$ and $1000^{\circ} \mathrm{C}$ which presented, respectively, strain-softening and fragile behavior. The positive influence of the preheating up to $75^{\circ} \mathrm{C}$ and $150^{\circ} \mathrm{C}$ on the mechanical performance of TRC was clearly noticeable along the entire course of stress-strain curves, mainly with relation to the tensile strength at the bend-over point (BOP) and, specially, to the multiple cracking pattern (Figure $1(\mathrm{~b}-\mathrm{c})$ ). This behavior was more pronounced for the temperature of $150^{\circ} \mathrm{C}$ where the TRC showed $\sigma_{\mathrm{BOP}} 92 \%$ greater than the TRC tested at room temperature. With relation to the ultimate tensile strength $\left(\sigma_{\mathrm{UTS}}\right)$, the contribution of the preheating up to $75^{\circ} \mathrm{C}$ and $150^{\circ} \mathrm{C}$ was not so significant, generating increases of, respectively, $10.7 \%$ and $13.4 \%$. At these temperatures the main process induced in the matrix by the thermal regime is the evaporation of free water. For temperatures greater than $150^{\circ} \mathrm{C}$, the stress level at the BOP and the ultimate tensile strength decreased gradually with increasing temperature. This decrease was accompanied by a significant reduction of the elastic modulus from $200^{\circ} \mathrm{C}$. The TRC heated to $200^{\circ} \mathrm{C}$ showed a multiple cracking pattern, similar to the $\mathrm{TRC}$ heated to $150^{\circ} \mathrm{C}$, however significant sings of strength deterioration were noticed above this temperature.
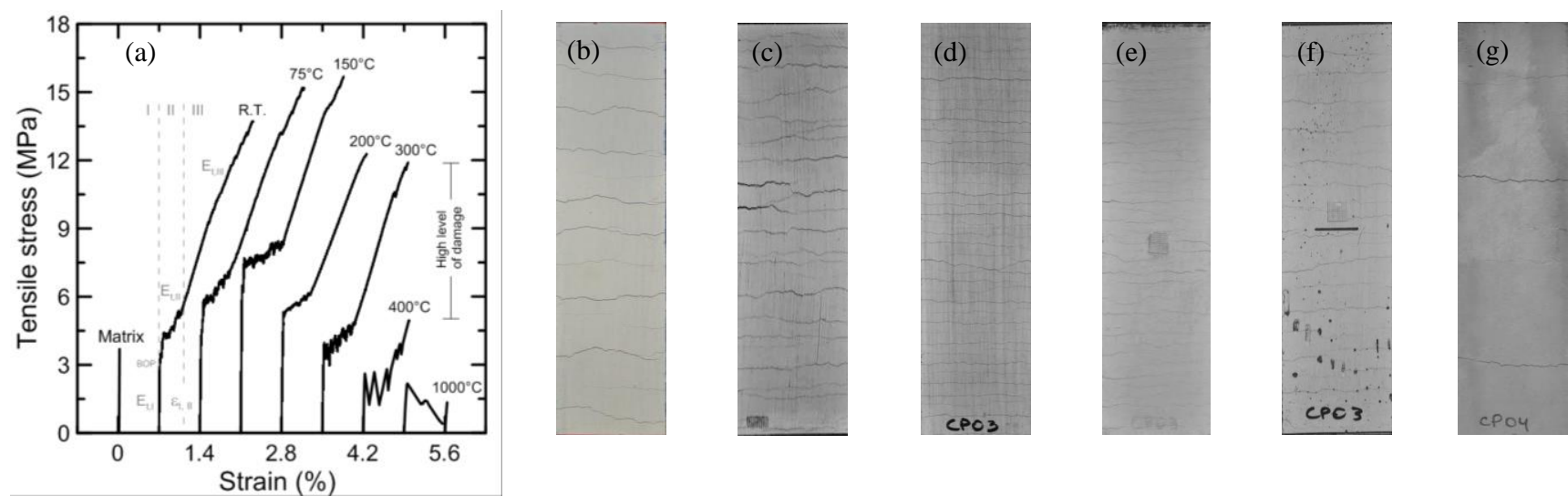

Figure 1: Influence of temperature on the (a) tensile stress curves of TRC's and in the cracking pattern at (b) room temperature and after heating process at (c) $75^{\circ} \mathrm{C}$, (d) $150^{\circ} \mathrm{C}$, (e) $200^{\circ} \mathrm{C}$, (f) $300^{\circ} \mathrm{C}$ and $(\mathrm{g}) 400^{\circ} \mathrm{C}$.

Table 2. Average results of the direct tensile test.

\begin{tabular}{|c|c|c|c|c|c|c|c|c|c|c|}
\hline \multirow{2}{*}{$\begin{array}{c}\text { Target } \\
\text { temperature }\end{array}$} & \multicolumn{4}{|c|}{ First crack values } & \multicolumn{6}{|c|}{ Post crack values } \\
\hline & $\begin{array}{l}\mathrm{P}_{\mathrm{BOP}} \\
(\mathrm{kN})\end{array}$ & $\begin{array}{c}\sigma_{\mathrm{BOP}} \\
(\mathrm{MPa})\end{array}$ & $\begin{array}{c}\varepsilon_{\mathrm{BOP}, \mathrm{I}} \\
(\%)\end{array}$ & $\begin{array}{c}\mathrm{E}_{\mathrm{t}, \mathrm{I}} \\
(\mathrm{GPa})\end{array}$ & $\begin{array}{l}P_{\text {UTS }} \\
(\mathrm{kN})\end{array}$ & $\begin{array}{c}\sigma_{\text {UTS }} \\
(\mathrm{MPa})\end{array}$ & $\begin{array}{c}\mathrm{E}_{\mathrm{t}, \mathrm{II}} \\
(\mathrm{GPa})\end{array}$ & $\begin{array}{c}\mathrm{E}_{\mathrm{t}, \mathrm{III}} \\
(\mathrm{GPa})\end{array}$ & $\begin{array}{l}\varepsilon_{\mathrm{t}, \mathrm{II}} \\
(\%)\end{array}$ & $\begin{array}{c}\varepsilon_{\mathrm{UTS}, \mathrm{III}} \\
(\%)\end{array}$ \\
\hline $25^{\circ} \mathrm{C}$ & 2.85 & 3.45 & 0.011 & 34.64 & 11.13 & 13.49 & 0.45 & 0.67 & 0.42 & 1.58 \\
\hline $75^{\circ} \mathrm{C}$ & 3.73 & 4.85 & 0.021 & 28.57 & 11.48 & 14.94 & 0.31 & 0.79 & 0.71 & 1.66 \\
\hline $150^{\circ} \mathrm{C}$ & 5.10 & 6.65 & 0.024 & 31.63 & 11.74 & 15.30 & 0.12 & 0.73 & 0.62 & 1.64 \\
\hline $200^{\circ} \mathrm{C}$ & 4.19 & 5.09 & 0.036 & 23.82 & 10.22 & 12.40 & 0.15 & 0.64 & 0.39 & 1.50 \\
\hline $300^{\circ} \mathrm{C}$ & 3.47 & 4.31 & 0.033 & 20.52 & 9.64 & 11.97 & 0.19 & 0.75 & 0.50 & 1.59 \\
\hline $400^{\circ} \mathrm{C}$ & 1.87 & 2.42 & 0.025 & 10.93 & 3.79 & 4.98 & 0.36 & 0.90 & 0.47 & 0.68 \\
\hline $600^{\circ} \mathrm{C}$ & 1.56 & 1.98 & 0.044 & 5.37 & - & - & - & - & - & - \\
\hline $1000^{\circ} \mathrm{C}$ & 1.10 & 1.33 & 0.037 & 3.96 & - & - & - & - & - & - \\
\hline
\end{tabular}

Studies using thermogravimetric analysis (TGA) showed that the loss in strength ranging from $150^{\circ} \mathrm{C}$ to $200^{\circ} \mathrm{C}$, can be explained by the end of the dehydration of metastable $\mathrm{CAH}_{10}\left(\mathrm{CaO} \cdot \mathrm{Al}_{2} \mathrm{O}_{3} \cdot 10 \mathrm{H}_{2} \mathrm{O}\right)$ and by the start of dehydration of the stables $\mathrm{AH}_{3}\left(\mathrm{Al}_{2} \mathrm{O}_{3} \cdot 3 \mathrm{H}_{2} \mathrm{O}\right)$ and $\mathrm{C}_{3} \mathrm{AH}_{6}\left(3 \mathrm{CaO} \cdot \mathrm{Al}_{2} \mathrm{O}_{3} \cdot 6 \mathrm{H}_{2} \mathrm{O}\right)$. For temperatures between $200^{\circ} \mathrm{C}$ and $300^{\circ} \mathrm{C}$, remaining hydrates $\mathrm{AH}_{3}$ and $\mathrm{C}_{3} \mathrm{AH}_{6}$ are almost completely dehydrated (also detected by TGA analyses) causing more losses in the elastic modulus and in the tensile strength. Between the target temperatures of $300^{\circ} \mathrm{C}$ and $400^{\circ} \mathrm{C}$ severe strength loss was observed. For temperatures greater than $400^{\circ} \mathrm{C}$ the specimens failed abruptly and large cracks occurred. At these temperatures, both the refractory matrix and basalt fabric showed significant signs of deterioration causing pronounced brittle behavior beyond the peak stress. The tensile strength of basalt fibers, as well as similar fibers (S-Glass fibers and E-Glass fibers) [4], decrease rapidly at temperatures greater than $400^{\circ} \mathrm{C}$. As a consequence, the thermo-mechanical behavior of the TRC was largely affected above this temperature. As reported previously, the TRC heated at $600^{\circ} \mathrm{C}$ showed a strain softening behavior. At this temperature, the minor crack-bridging action of the fibers could be neglected if compared to the results at the lower target temperatures. The composite heated at $1000^{\circ} \mathrm{C}$, however, showed fragile failure. This brittle behavior is attributed, in part, to the melting of the filaments in the yarns that occurred for lower temperatures than those defined by the manufacturer (about $1350^{\circ} \mathrm{C}$ ). The average tensile strength for the composite heated at $1000^{\circ} \mathrm{C}$ at the first crack was $1.33 \mathrm{MPa}, 38.5 \%$ of the $\sigma_{\mathrm{BOP}}$ at room temperature. There was no visible concrete spalling for any one of the used target temperatures $(75,150,200,300$, $400,600 \mathrm{e} 1000^{\circ} \mathrm{C}$ ), even with samples in the saturated condition. This can be attributed to the small thickness of the samples and to the textile reinforcement that creates relieve channels to the internal vapor pressure present in the concrete pores. A micro-structural investigation using the SEM was carried out to confirm the damage process on the TRC discussed previously. Figure 2 shows fibre-matrix interface micrographs of the basalt yarns in its natural condition (Figure 2 (a)) and 
after exposure to $200^{\circ} \mathrm{C}, 400^{\circ} \mathrm{C}$ and $1000^{\circ} \mathrm{C}$. At $75^{\circ} \mathrm{C}$ the styrene-acrylic latex coating starts to transforms from visco-elastic to plastic, thus, impregnating more strongly the matrix and the internal filaments. At this temperature a pronounced merging of polymer towards the matrix occurs. Between $75^{\circ} \mathrm{C}$ and $150^{\circ} \mathrm{C}$, as the temperature is not able to decompose the polymer, after cooled, the styrene-acrylic latex becomes stiffer and visco-elastic again. The newly generated polymer interlocks change the interface mechanisms on the TRC increasing the cross links between the fibers and matrix. As reported in previous researches $[8,5]$, the penetration of coating in the yarn, in this case due to the heating regime, makes pronounced changes in the composite behavior. This occurs because the filaments are stressed more equally, taking part in the load support and, consequently, increasing the tensile stress. Furthermore, the irreversible shrinkage of the hardened paste (between $25^{\circ} \mathrm{C}$ and $\sim 200^{\circ} \mathrm{C}$ ) [7, 9], that remains after cooling down the material, can lead to an improve in the bond between the fibers and matrix. This microstructure evolution occurs due to the evaporation mechanism of free water and the dehydration of calcium aluminate hydrates and is accompanied by micro-cracking in the paste. The first signs of degradation of the polymer started to appear at $200^{\circ} \mathrm{C}$. From the Figure 2 (b) (TRC preheated at $200^{\circ} \mathrm{C}$ ) it can be seen that the coating between the fibers is porous and presents less interlocks than the coating at the room temperature. At $200^{\circ} \mathrm{C}$ the copolymer take the form of thin-films or scales deposited over the filaments. As a result of the less amount of coating between the fibers and in the fiber-matrix interfaces, significant strength losses were observed. This means that even though the fiber content remain constant the presence of coating can become a deterministic factor in the tensile response of the composite. At $300^{\circ} \mathrm{C}$, the polymer is still present, however, the thin layers of polymer almost disappear. Figure 2 (c) shows that the coating surrounding the fibers was entirely lost at $400^{\circ} \mathrm{C}$. As a consequence, the tensile behavior of the TRC change leading to a reduced crack-widening phase (stage III) and a sudden drop in the serviceability limit of the composite. After preheating up to $600^{\circ} \mathrm{C}$, both matrix and textile shown to be weakened by the heating regime resulting in a strain softening behavior due to the sliding of the fibers. Figure 2 (d) shows the fibre-matrix interface micrographs highlighting the volumetric variation caused by the target temperature of $1000^{\circ} \mathrm{C}$ to the filaments.
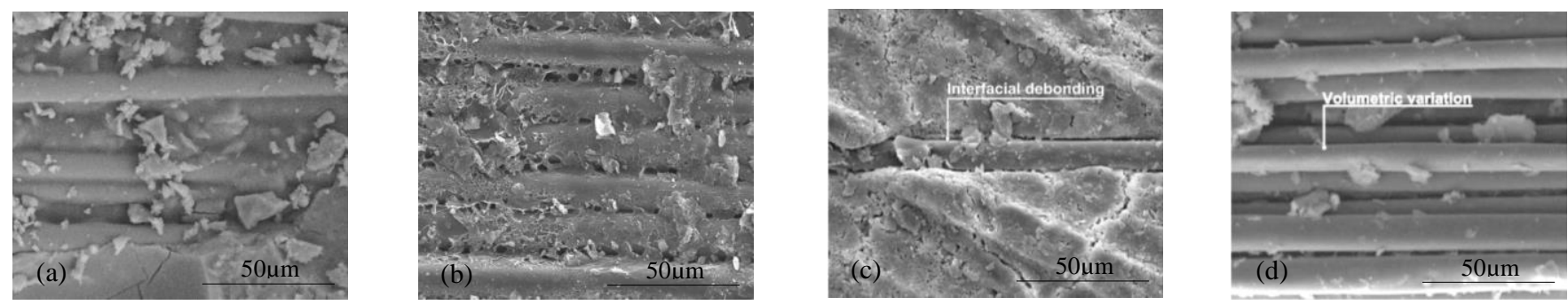

Figure 2: Fiber-matrix interface: (a) in its natural condition and after exposure to temperatures of (b) $200^{\circ} \mathrm{C}$, (c) $400^{\circ} \mathrm{C}$ and (d) $1000^{\circ} \mathrm{C}$.

\section{Conclusions}

The experimental investigation shows that the mechanical residual properties of the TRC exposed to high temperatures depend on the loss in strength of the matrix and of the fabric. Furthermore, the coating was strongly affected by the heating regime changing the fiber-matrix bonding properties at certain temperatures. At temperatures up to $150^{\circ} \mathrm{C}$ the soften and restiffen mechanism of copolymer helped in generating more efficient cross links between the fibers and matrix. At higher temperatures $\left(400\right.$ and $600^{\circ} \mathrm{C}$ ), the remaining coating was completely deteriorated and the behavior of TRC became brittle.

\section{Acknowledgements}

The authors gratefully acknowledge the Brazilian Agency CNPq for its partial financial support.

\section{References}

1. Mechtcherine V. Novel cement-based composites for the strengthening and repair of concrete structures. Review Article. Construction and Building Materials. 41 (2013) 365-373.

2. Soranakom C, Mobasher B. Geometrical and mechanical aspects of fabric bonding and pullout in cement composites. Materials and Structures. 42 (2009) 765-777.

3. Krüger M, Reinhardt HW. (2006) Chapter 6: Fire resistance. In: Report 36: Textile Reinforced Concrete - State-of-the-Art Report of RILEM Technical Committee 201-TRC. Ed: Wolfgang Brameshuber.

4. Silva FA, Butler M, Hempel S, Toledo RD, Mechtcherine V. Effects of elevated temperatures on the interface properties of carbon textile-reinforced concrete. Cement \& Concrete Composites. 48 (2014) 26-34.

5. Reinhardt HW. On the Biaxial Testing and Strength of Coated Fabrics. Experimental Mechanics. 16 (1976) $71-74$.

6. De Larrard F. (1999)Concrete mixture proportioning: a scientific approach. London. E\&FN SPON.

7. Sedran T. Rhéologie et rhéométrie des bétons: application aux bétons autonivelants. Doctoral dissertation. Ecole Nationale des Ponts et Chaussées. (1999) $484 \mathrm{p}$.

8. Köckritz U, Offermann P, Jesse F, Curbach M. Influence of textile manufacturing technology on load bearing behavior of textile reinforced concrete. In: Proceedings of the 13th International Techtextile-Symposium. (2005).

9. Innocenti MDM, Cardoso FA, Akyioshi MM, Pandolfelli VC. Drying Stages during heating of high-alumina. Ultra-low-cement refractory castables. Journal of the American Ceramic Society. 86 (2003) 1146-1148. 